\title{
P04
}

\section{Investigation of Sabalan Geothermal Field Structure Magnetotelluric Method (MT)}

\section{A. Fazelvalipour* (Islamic Azad University Mashhad Branch Iran)}

\section{SUMMARY}

Sabalan geothermal field is a high potential geothermal system in Ardebil province N-W of Iran that is now under investigation for the electricity power generation. In this paper the fourteen MT stations of 1998 MT data set were used along a profile perpendicular to the main geological structures in order to assess the three main elements of Sabalan geothermal field namely cap-rock, reservoir and heat source. TE and TM mode data and skew parameter show that the earth dimensionality differs from site to site, so we examine the joint 2D inversion along the profile. The two-dimensional inversion has been done by using a code from Siripunvaraporn and Egbert (2000). The resulting model show a pattern of high-very low-low resistivity with depth. The high resistive layer at the surface is governed to a great extent by basalt, andesitic and old trachyandesitic flows and other impermeable rocks that have thermal conduction and acts as the cap-rock of the system. The second layer is a very conductive layer and interpreted as the reservoir with thermal convection and hot fluids contained in its fractured and pores 
Investigation of Sabalan geothermal field structure Magnetotelluric method(MT)

\title{
Ardalan Fazelvalipour1, Yalda Vejdani2
}

\author{
Islamic azad university , mashhad branch, iran , department of geology, faculty of \\ science1, 2 \\ dra_fv@yahoo.com \\ yaldavejdani@gmail.com
}

\begin{abstract}
Sabalan geothermal field is a high potential geothermal system in Ardebil province N-W of Iran that is now under investigation for the electricity power generation .In this paper the fourteen MT stations of 1998 MT data set were used along a profile perpendicular to the main geological structures in order to assess the three main elements of Sabalan geothermal field namely cap-rock, reservoir and heat source. TE and TM mode data and skew parameter show that the earth dimensionality differs from site to site, so we examine the joint 2D inversion along the profile. The two-dimensional inversion has been done by using a code from Siripunvaraporn and Egbert (2000). The resulting model show a pattern of high-very low-low resistivity with depth. The high resistive layer at the surface is governed to a great extent by basalt, andesitic and old trachyandesitic flows and other impermeable rocks that have thermal conduction and acts as the cap-rock of the system. The second layer is a very conductive layer and interpreted as the reservoir with thermal convection and hot fluids contained in its fractured and pores. The resistive basement is a hot and solid magmatic intrusion and interpreted as a heat source that produces a conductive heat flow towards the reservoir. As a result, the shallow resistivity model of Sabalan area is in a good correlation with the geological features and the common conceptual resistivity model for the geothermal reservoir structure.
\end{abstract}

Keywords: Magnetotelluric, Geothermal, Reservior, 2D inversion, Sabalan, Iran 